\title{
Intracranial Tuberculous Subdural Empyema in a Child: Case Report
}

\author{
Teegala Ramesh ${ }^{1}$, Manaswini Das ${ }^{2 *}$
}

${ }^{1}$ Professor of Neurosurgery, ASRAM Medical College and Hospital, Eluru, Andhra Pradesh

${ }^{2}$ Associate Professor, Dept of Microbiology, ASRAM Medical College, Eluru, Andhra Pradesh

DOI: $10.36348 / \mathrm{sjpm} .2020 . \mathrm{v} 05 \mathrm{i01} .006$

| Received: 18.01 .2020 | Accepted: 26.01 .2020 | Published: 30.01 .2020

*Corresponding author: Manaswini Das

\section{Abstract}

Intracranial tuberculous subdural empyema originating from otitis media and mastoiditis is rare. Timely diagnosis and prompt surgical management, followed by microbiological confirmation of the causative agent is known to be lifesaving. We report a case of a 10-year old child with subdural empyema with fronto-parietal involvement, who was managed by craniotomy and antitubercular therapy was instituted after microbiological investigations. We urge the necessity of clinical suspicion and immediate surgery for management of such cases.

Keywords: Subdural empyema, tuberculous otitis media.

Copyright @ 2020: This is an open-access article distributed under the terms of the Creative Commons Attribution license which permits unrestricted use, distribution, and reproduction in any medium for non-commercial use (NonCommercial, or CC-BY-NC) provided the original author and sources are credited.

\section{INTRODUCTION}

Intracranial subdural empyema is a neurosurgical emergency, a rare infectious disorder with a high mortality rate. It has been seen most frequently as a complication of sinusitis, or less frequently, otitis media or neurosurgical procedures [1]. Prompt surgical drainage with appropriate antimicrobial therapy is required to improve mortality and morbidity rates.

\section{CASE REPORT}

A 10-year-old girl presented to the Neurosurgery outpatient department with complaints of fever and headache associated with multiple episodes of projectile vomiting of four days duration. She had one episode of generalised tonic clonic seizures with postictal drowsiness. She has had a past history of chronic purulent discharge from the left ear of 7 years duration which was inadequately treated. There was no past or family history of tuberculosis. The general examination revealed a febrile patient with minimal purulent discharge from the left ear. There was no periorbital swelling or neck stiffness. There was painless upper jugular cervical lymphadenopathy. A neurological examination revealed a Glasgow Coma Scale score of E4V2M6 and no signs of meningism.

On haematological examination, the erythrocyte sedimentation rate and the white blood cell counts were found to be elevated. HIV serology was found to be non-reactive. The chest radiograph did not reveal any signs of old healed or active lesions of tuberculosis. Computed tomography (CT) scan Brain Plain and Contrast study revealed a thin walled hypodense rim enhancing lesion in the left frontoparietal region. There was effacement of the sulci suggestive of cerebral edema. The magnetic resonance imaging (MRI) Brain Plain and Contrast revealed a 5.85 X 7 X $3 \mathrm{~cm}$ large rim enhancing extra axial altered signal intensity space occupying lesion (SOL) in the left temporo fronto parietal region.

A left fronto-parietal craniotomy was performed and the subdural empyema evacuated. The adjacent calvarium was normal. The empyema spread all along the basal dura in the fronto temporal area. About $50 \mathrm{ml}$ of thick straw-colored pus was drained and sent for microbiological and histopathological examinations. The patient was started on empirical high dose antibiotics (Cefoperazone $60 \mathrm{mg} / \mathrm{kg} /$ day + Sulbactum, Amikacin $50 \mathrm{mg} / \mathrm{kg}$ and Metronidazole $25 \mathrm{mg} / \mathrm{kg} /$ day) awaiting microbiological results. Anticonvulsant therapy was started (Phenytoin 8 $\mathrm{mg} / \mathrm{kg} /$ day).

Aerobic culture of the pus sample from the subdural empyema and left ear swabs were found to be sterile. Gram staining did not reveal any microorganisms. Ziehl-Neelsen staining of the pus from the subdural empyema revealed numerous acid-fast bacilli (Fig 1). Ziehl-Neelsen staining of the pus from the left ear showed scanty acid-fast bacilli (Fig 2). Histopathological examination showed granulation tissue with caseous necrotic material and clusters of 
epithelioid cells (Fig 3). Lumbar puncture was performed when the patient was stable and the CSF showed pleocytosis.

The intravenous antibiotics were continued for 5 days. Antituberculous treatment was started with $10 \mathrm{mg} / \mathrm{kg}$ of rifampicin, $5 \mathrm{mg} / \mathrm{kg}$ of isoniazid, $25 \mathrm{mg} / \mathrm{kg}$ of pyrazinamide, $20 \mathrm{mg} / \mathrm{kg}$ of ethambutol and $40 \mathrm{mg}$ of pyridoxine to be continued for 12 months. The patient was stable and was discharged on the $15^{\text {th }}$ postoperative day. She was advised to present for monthly follow-up.

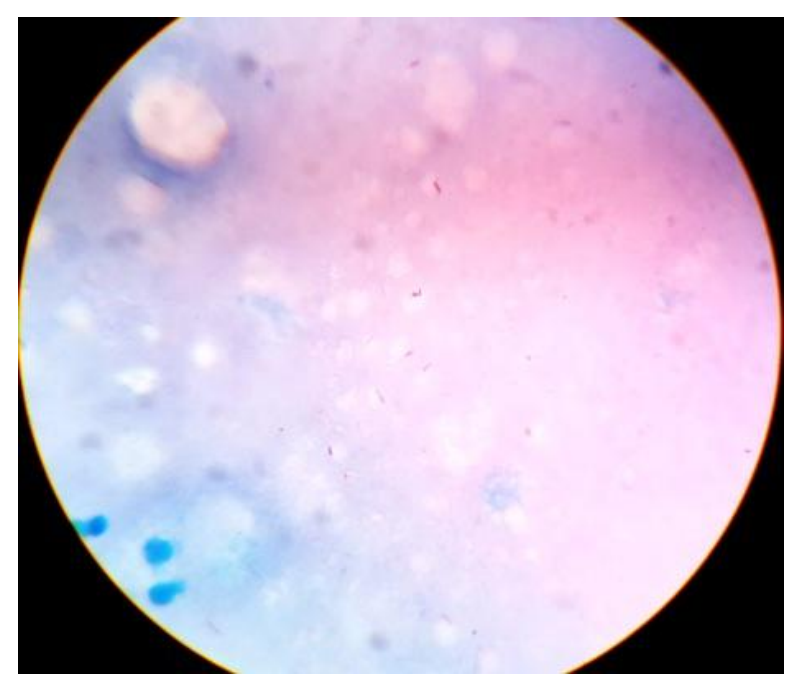

Fig-1: Pus from the subdural empyema shows numerous acid-fast bacilli

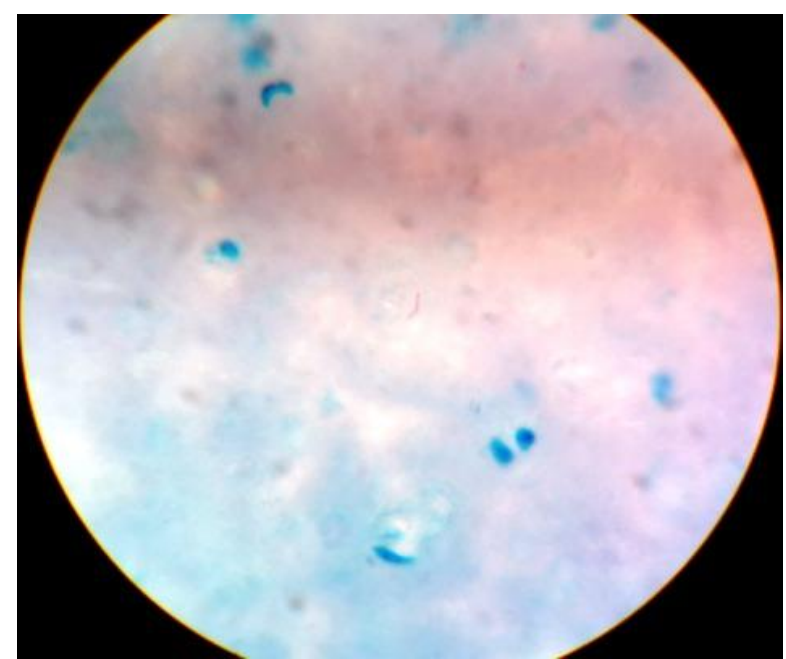

Fig-2: Pus from the left ear shows acid fast bacilli

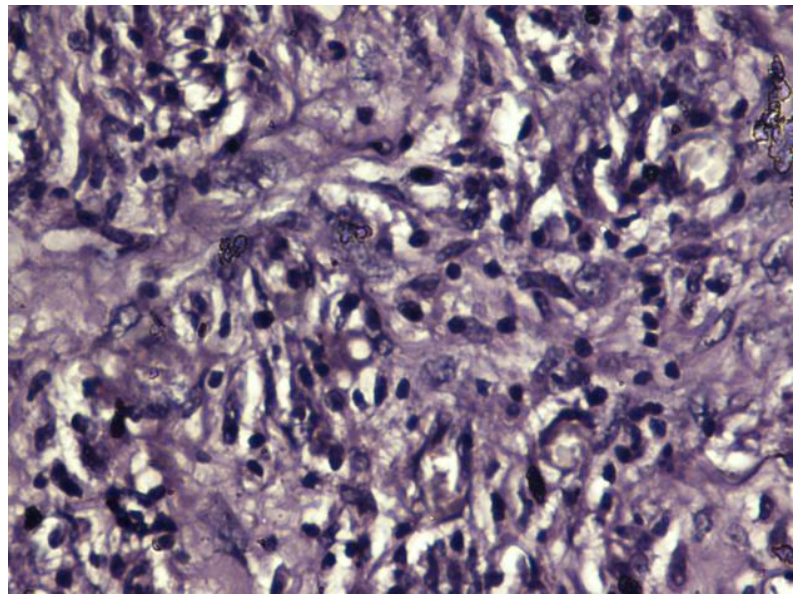

Fig-3: Histopathological picture of the subdural empyema
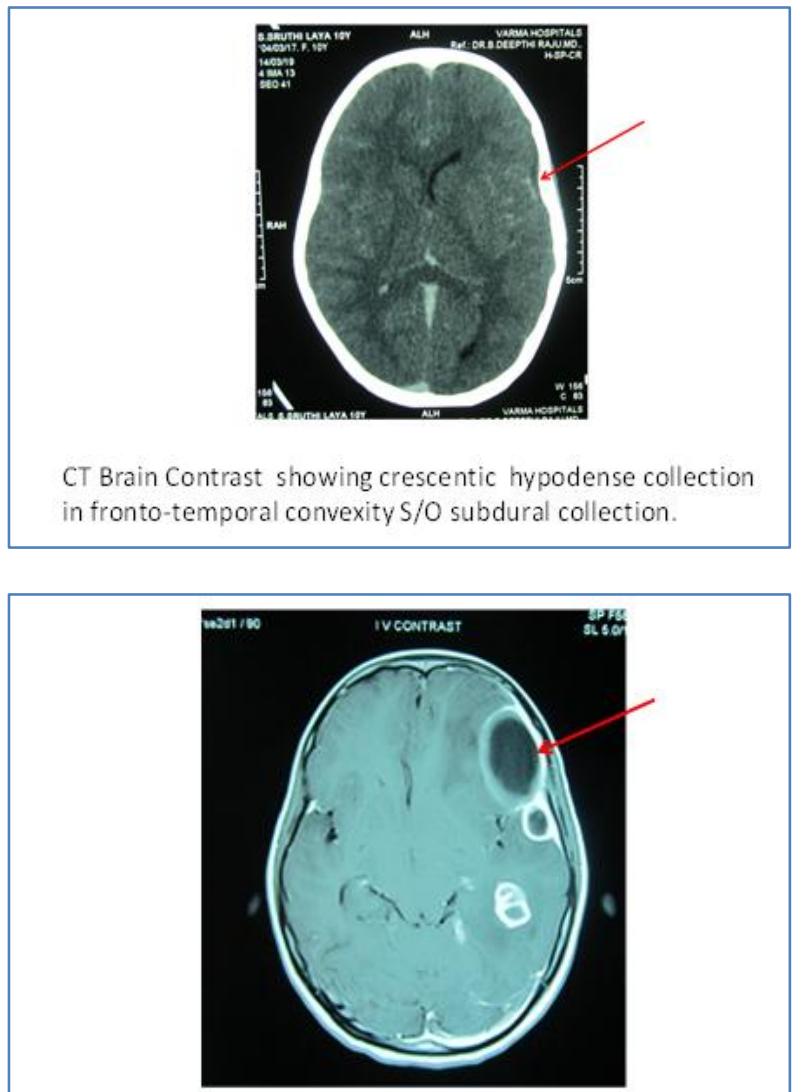

MRI of Brain Contrast showing ring-enhancing lesion in temporo-frontal region. Bucking of brain tissue adjacent to lesion S/O extra-axial collection. 


\section{DISCUSSION}

Subdural empyema is a loculated infection which may occur intracranially or in the spinal canal. It accounts for $15-20 \%$ of all localized intracranial infections [2]. Intracranial subdural empyema occurs secondary to paranasal sinusitis, meningitis, otitis media and mastoiditis, trauma, brain surgery, or via haematogenous spread [3]. It mostly affects children and young adults, nearly $70 \%$ cases occur in the second and third decades of life [1].

Initial signs of fever and focal headache progress to vomiting and altered sensorium as the infection progresses [1]. Focal neurologic signs appear in 24-48 hours and progress rapidly, with involvement of the entire cerebral hemisphere. Seizures (either focal or generalized are seen in $25 \%$ to $80 \%$ of cases [4]. Computed tomography (CT) with contrast or magnetic resonance imaging (MRI) is diagnostic procedures for subdural empyema, MRI being able to provide better clarity of morphologic detail.

Intracranial complications of suppurative otitis media range from about $0.24 \%$ to $1.97 \%$ [5]. The mastoid and middle ear are the source of subdural empyemas in $10-20 \%$ of patients, especially in localities where cases of otitis media are not treated promptly with antimicrobial therapy [2]. Microorganisms spread from the mastoid through retrograde septic thrombophlebitis of the emissary veins, through defect in the tegmen tympani or via haematogenous route.

Craniotomy is the preferred method of drainage of purulent material in subdural empyemas (good outcome in $86.1 \% ; P=0.001$ ) Mortality rates have been found to be higher for patients only with drainage via burr holes $(23.3 \%)$, compared with those who underwent craniectomies $(11.5 \%)$ or craniotomies $(8.4 \%)$ [6]. Patients who have undergone multiple burr hole or craniectomy drainage require frequent operations to drain recurrent or remaining pus. These procedures are recommended for cases with septic shock, localized parafalcine collections and in children with subdural empyemas secondary to meningitis [2].

A number of bacterial species have been isolated in intracranial subdural empyema, the commonest being aerobic streptococci (25-45\%), staphylococci $(10-15 \%)$ and anaerobes. Polymicrobial infections are common. Once purulent material has been aspirated, antimicrobial therapy is initiated based on the microscopy results. Aerobic and anaerobic cultures help to guide the use of specific antimicrobials.

Tuberculosis continues to be a major health concern in India. Tuberculous otitis media is a rare entity. In developing communities it can account for upto $4 \%$ of all otitis media cases [7]. It should be considered in cases with persistent suppurative otitis media unresponsive to antibiotics. Delay in diagnosis due to unrecognised and therefore untreated tuberculous otitis media invariably leads to complications, as seen in the present case. Meningitis, sigmoid sinus thrombosis, tuberculoma and abscesses are the more common complications associated with tuberculous otitis media. There are few reports of intracranial subdural empyema due to tuberculous bacilli [8-10].

Mortality due to subdural empyema was nearly $100 \%$ in the pre-antibiotic era and is now approximately $10-20 \%$, with the current methods of diagnosis and treatment [2]. Survival rates in patients with intracranial subdural empyema is greater than $90 \%$ for those who are awake and alert at presentation but less than $50 \%$ for those who are unresponsive to pain. Surgical drainage of tuberculous subdural empyema to relieve mass effect and microbiological confirmation of the causative agent is imperative.

A high index of clinical suspicion and early removal of the focus of infection and appropriate systemic antimicrobial therapy improves the mortality and morbidity rate in cases of intracranial subdural empyema.

\section{ACKNOWLEDGEMENTS}

We thank Dr U Sreenivasa Rao and Dr Sangeeta Panigrahi for their invaluable help in preparation of the manuscript. We thank Ms Swathi and Ms Sakuntala for technical support. We would also like to thank ASRAM Hospital authorities for their permission to publish this article.

\section{REFERENCES}

1. Greenlee, J. E. (2003). Subdural empyema. Current treatment options in Neurology, 5: 13-22

2. Tunkel, A.R. (2010). Subdural empyema, Epidural abscess and Suppurative Intracranial thrombophlebitis. In: Mandell GL, Bennett JE, Dolin R (eds). Principles and Practice of Infectious Diseases. $7^{\text {th }}$ edn, 1279-1287

3. Yoon, K.S., Yee, G.T., Han, S.R., Lee, C.H. (2010). Escherichia coli subdural empyema following subdural hygroma in elderly patient. J Korean Neurosurg Soc, 47(6): 470-472

4. Osborn, M.K., Steinberg, J.P. (2007). Subdural empyema and other suppurative complications of paranasal sinusitis. Lancet Infect Dis, 7: 62-67

5. Osma, U., Cureoglu, S., Hosoglu, S. (2000). The complications of chronic otitis media: report of 93 cases. Journal of Laryngology \& Otology, 114(2): 97-100

6. Nathoo, N., Nadvi, S.S., and Gouws, E., Van, Dellen, J.R.(2001). Craniotomy improves outcomes for cranial subdural empyemas: computed tomography era experience with 699 patients. Neurosurger, 49: 872-878 
7. Awan, M.S., Salahuddin, I. (2002). Tuberculous otitis media: two case reports and literature review. Ear Nose Throat J, 81: 792-794

8. Van, Dellen, A., Nadvi, S.S., Nathoo, N., Ramdial, P.K. (1998). Intracranial tuberculous subdural empyema: case report. Neurosurgery, 43(2): 370373.

9. Cayli, S.R., Onal, C., Kocak, A., Onmus, S.H., Tekiner, A. (2001). An unusual presentation of neurotuberculosis:subdural empyema. Case report. J Neurosurg, 94(6): 988-991

10. Banerjee, A.D., Pandey, P., Ambekar, S., Chandramouli, B.A. (2010). Paediatric intracranial subdural empyema caused by Mycobacterium tuberculosis-a case report and review of literature. Child's nervous System, 26(8): 1117-1120. 